\title{
Sobre Andrea de Cervantes
}

\author{
KRZYSZTOF SLIWA*
}

Andrea de Cervantes, hija mayor de Rodrigo de Cervantes, sordo desde la infancia, y de Leonor de Cortinas, fue bautizada el 24 de noviembre de 1544 en la iglesia de Santa María la Mayor de Alcalá de Henares, siendo su compadre mayor Melchor Méndez y comadre Luisa de Contreras, su mujer.

Sobre la hermana del autor del Quijote hay 25 documentos legales, pero no existe ningún esbozo completo de su perfil. Se ignora su niñez, adolescencia, educación y profesión. Es hipotético que asistiera a algún tipo de escuela junto con su hermano Miguel y su primo Andrés, al vivir en Cabra al lado de su tío Andrés de Cervantes, alcalde mayor de Cabra, ya que a esta sazón cumplía los dieciocho de su edad.

Andrea ha de haber tenido que pasar por mucho dolor cuando su padre Rodrigo estaba en la prisión pública de Valladolid y su madre, Leonor, a su vez, daba a luz a su hermana Magdalena de Pimentel y Sotomayor en la ciudad del Pisuerga. Sin embargo, era la nieta predilecta y favorecida de la abuela paterna, Leonor Fernández de Torreblanca, puesto que ésta le manda "el terçio e rremanente del quinto de todos sus bienes rraizes e muebles, titulos, derechos e açiones, lo qual le mando de mejoria mas que a los otros mis herederos en la mejor manera que de derecho a lugar" (José de la Torre y del Cerro, Cinco documentos cervantinos, 14-17).

La hermana del manco de Lepanto estuvo casada "tres veces", y quedó "viuda del general Álvaro Mendaño". Sin embargo, no ha sido posible rastrear la existencia de ningún general llamado Álvaro Mendaño.

Pero ya al tener veinte abriles, tuvo que haber cautivado a cierto Nicolás de Ovando. Se desconoce la personalidad de este Ovando; pero fruto de

* Fayetteville State University. 
aquellos amores infelices fue Constanza, quien unas veces se apellidó "de Ovando", y otras "de Figueroa". De ella hay unos 15 documentos legales. Se piensa que en el Monasterio de Santa Paula de Sevilla, tomó el hábito una Mariana de San José en 1593, hija de Juan de Padilla Carreño y de Melchora de Ovando y Figueroa, y es lógico presumir que ésta fuese hermana o parienta muy próxima de tal Nicolás.

Los amores de Nicolás con Andrea debieron de tener en su inicio intención honesta; sin embargo, adelante se comprende que en el proceso del caballero de Santiago, Gaspar de Ezpeleta en Valladolid, ella declaró, el 30 de junio de 1605, ser "viuda, mujer que fue de Sante Ambrosio, florentín, y que antes fue desposada y concertada con Nicolás de Ovando", pero la distinción prueba no haber sido nunca su esposa legítima. En efecto, las relaciones con él (quien le engañó) cobraron carácter de intimidad antes de consumarse el sacramento del matrimonio.

La perspicaz Andrea paró en principio el golpe, pues, el 6 de marzo acudió ante el alcalde ordinario, Alonso de Torres, y señaló que "en cierto pleito y causa que ante el dicho señor alcalde trata y sigue contra el dicho su padre Francisco de Chaves, sobre ciertas causas e razones ella quiere entrar como tercera opositora a los bienes embargados o secretados por del dicho su padre, que a ella le pertenecen por ciertos derechos e acciones, e por ser como es menor de la dicha edad de veinte e cinco años, tiene necesidad de ser proveída de un curador" (Francisco Rodríguez Marín, Cervantes estudió en Sevilla, $15,16,35-36)$.

En estos documentos, se llama hija "de Rodrigo de Cervantes, de edad que dijo ser de diez e siete años poco más o menos... e ansi lo pareció por su azpeto". Lo parecería, efectivamente, por el azpeto; pero había cumplido ya los veinte. Prolongaba con garbo las huellas de su tía María de Cervantes, amante de don Martín de Mendoza, el Gitano, aunque es común y tan antiguo como el mundo el achaque mujeril de rebajarse la edad. Se le aceptó el curador que nombraba, en la persona del escribano de Sevilla Alonso de las Casas. A la llegada de Rodrigo, proseguiría el pleito, cuyos resultados se ignoran.

Cabe preguntar: ¿qué derechos y acciones eran los alegados por Andrea, para pertenecerle los bienes embargados o secuestrados como de su padre? ¿No serían larguezas de su novio Nicolás de Ovando, extremadas durante los siete u ocho meses de ausencia de aquél? Como quiera que fuese, lo positivo es que Andrea misma dice que estuvo "concertada", quizá amonestada, con Ovando; pero éste, quien tuvo de ella a Constanza, jamás contrajo matrimonio con Andrea. Inútilmente, Magdalena de Cervantes, en el proceso por la muerte de Gaspar de Ezpeleta, afirma que Constanza es "hija legítima de Andrea". La documentación cervantina pone de manifiesto esta falsedad. Nicolás de Ovando se portó villanamente.

¿Cuándo nació Constanza? Es un misterio, como muchas fases de su vida, así como en los casos de Miguel de Cervantes Saavedra y sus parientes. ¿Dónde? Es un misterio también. El nacimiento debió de acaecer en el año 1565 o en el entrante, 1566; pero ni en Sevilla, lugar indudable de los amores 
de Andrea y Ovando, ni en Madrid, adonde enseguida se trasladó Rodrigo, se ha descubierto la partida bautismal.

Concurren, pues, circunstancias anómalas en este nacimiento, que sabe Dios dónde ocurriría, y que, contingentemente, se mantuvo oculto algunos años. El secreto que envuelven los juveniles de Constanza ha dado origen a no pocas fantasías en los biógrafos, aduciendo pasajes cervantinos en los cuales aparece Constanza, y relacionándolos con ella. La oscuridad del nacimiento promueve dificultades en el cómputo de la edad; aunque no de imposible dilucidación. En un documento otorgado por Constanza el 8 de diciembre de 1596, ella expresa ser menor de veinticinco años, a tenor de lo cual se diría nacida después de 1571. Ella misma anula esta data, al confesar en la causa de Gaspar de Ezpeleta, el 30 de junio de 1605, tener "veinte e ocho años". Pero lo más seguro para inferir la edad de ella es el documento de su curaduría en favor de su madre. El 12 de octubre de 1576, Andrea alega que su hija "es menor de doce años y mayor de seis" (Cristóbal Pérez Pastor, 1, documento 10). Tomando, pues, un término medio, nos da la fecha de 1565 o 1566 , o sea justamente la que asignamos a su nacimiento.

El novio de Andrea no era de Sevilla, sino natural de Cáceres, antiguo y noble solar de la ilustre familia de los Ovando, que produjo al famoso Capitán Diego de Cáceres Ovando; al menos famoso Nicolás de Ovando, gobernador de la Isla Española y comendador mayor de Alcántara, y al referido provisor de Sevilla. Pero Nicolás de Ovando llevó este nombre en recuerdo del mencionado gobernador de la Isla Española. Debió de nacer en 1544 ó 1545. Era primogénito del doctor en Leyes Luis Carrillo, caballero de la Orden de Santiago, del Consejo de Su Majestad y alcalde de su casa y Corte, y de la ilustre señora María de Ovando, los cuales engendraron, además, otros cinco hijos, a saber: Luis Carrillo, Bernal Francés de Zúñiga, Isabel Carrillo, Juana de Ovando y Juan de Ovando, quien falleció en la infancia.

Indudablemente, se observa a través de toda la documentación de Nicolás de Ovando que era hijo de casa rica y mayorazgo con el más lisonjero porvenir. Eso resultaba un partido inmejorable para Andrea, siendo primogénito de un alcalde de Casa y Corte e individuo del Consejo Real, descendiente de una de las más ilustres casas de Extremadura. No es extraño que Andrea se cegara, y que el padre de Miguel de Cervantes, y aun Cervantes mismo, vieran con buenos ojos aquellas relaciones, si bien comenzaban a izquierdear y acabaron torciéndose por completo, quizá sin culpa entera de nadie, sino por intervención del destino y la mala ventura que enseguida acaeció.

Nicolás de Ovando tuvo que haber prometido reparar su falta, aunque sus progenitores se opondrían a un matrimonio socialmente tan desigual; y por eso ella sólo miente a medias al decir que estuvo "desposada y concertada" con él. Desposada, no; concertada, evidentemente; pero como escribirá el insigne Miguel de Cervantes "cuando traen las desgracias la corriente de las estrellas, como vienen de alto abajo despeñándose con furor y con violencia, no hay fuerza en la tierra que las detenga, ni industria humana que prevenirlas pueda" (Quijote, 1, capítulo XXVII). 
En resolución, el concierto con Andrea no pasó a desposorio. Nicolás, incapaz de reaccionar contra los prejuicios sociales, mayormente en esta sazón, se apartó de su prometida. Andrea, burlada, despechada o para atraerle, aceptó nuevos amores. Mas Ovando persistió en su alejamiento. Y sobrevenido lo irremediable, ya que quedaba su hija, Constanza, se haría la consiguiente escritura de donación, a satisfacer cuando él cobrara su hacienda, único recurso, por las buenas, en estos casos, a que solía preceder la amenaza de demanda ante el vicario, si no se cumplía la palabra de casamiento. Aceptado el convenio, con el natural dolor, se fijarían los plazos.

El 22 de agosto le fue discernida la tutela "a la ilustre señora doña María de Ovando, de las personas y bienes de los menores sus hijos". Pero la justicia de Dios es inmanente. Si Nicolás de Ovando dejaba a una hermana de Cervantes compuesta, sin novio y deshonrada por añadidura, otro calaverón, pariente del mismo Ovando, dejaba a su vez a su hermana Isabel, compuesta también y sin novio, y, si no deshonrada, con gran escándalo en la familia y obligada a entrar en un convento, y de una manera muy rara fueron acontecimientos que tuvieron lugar por los mismos días.

Ese año se descubre otro episodio, al parecer amoroso, de Andrea de Cervantes. Un gentilhombre italiano, Juan Francisco Locadelo, en compañía de Andrea, comparece el 9 de junio ante el escribano Francisco Ortiz y dice que "por cuanto yo tengo mucha obligación e soy en mucho cargo a la señora doña Andrea de Cervantes, hija de Rodrigo de Cervantes, residente en esta villa e corte, ansí porque estando yo ausente de mi natural en esta tierra me ha regalado y curado algunas enfermedades que he tenido, ansi ella como su padre e hecho por mí y en mi utilidad otras cosas de que yo tengo obligación a lo remunerar y gratificar", le hace donación e irrevocable de los bienes y cosas siguientes:

"Siete piezas de tafetanes amarillos y colorados (que años después hubo de empeñar Miguel), un jubón de telilla de plata, guarnecido de negro y oro, de tela de oro carmesí, seis cofias de oro y plata, otro, un cordón y un rosario de cristal, y ochenta pintas y una argolla de cristal, dos escritorios, el uno de Flandes, diez lienzos de Flandes, seis almohadas de Holanda y Rúan, 300 escudos de oro en oro". O sea toda una casa puesta con lujo, más la gran suma de escudos de oro y agrega: "los cuales dichos bienes de suso declarados le doy por las causas susodichas e por otras muchas buenas obras que della he recibido e porque tenga mejor con qué se poder casar e honrar e para ayuda al dicho su casamiento, sin que en ellos otra alguna persona, ni sus padres, ni hermanos, ni alguno dellos, tenga ni haya cosa alguna contra la voluntad de la dicha D. ${ }^{a}$ Andrea..., con tanto que si los dichos sus padres o hermanos o alguno de ellos o otra cualquier persona se entremetiere a se los tomar o quitar, todo o parte dellos, o hacerle sobrellos otra molestia o vejación alguna por el mismo caso, desde luego esta donación quede e sea en sí ninguna e de ningún valor y efecto... " (Cristóbal Pérez Pastor, 1, documento 3).

Pérez Pastor cree que "aunque esta donación no se hizo propter nuptias, estaba destinada ad nuptias contrahendas, las cuales se debieron verificar poco tiempo después". 
Para el 1 de septiembre de 1573, Andrea vivía aparte con su hija Constanza, y se dedicaba a trabajos de costura y recibía de aprendiz, mediante condiciones, por dos años, a Isabel de Alvear, a cuya madre entregó a cuenta 44 reales y le restaba doce ducados, que le pagaría al fin del tiempo. Las condiciones eran las siguientes:

\footnotetext{
"en este especio de dos años la habéis de dar de comer e beber e vestir e calzar honestamente a vuestra elección y voluntad, conforme a la calidad de la dicha mi hija, y casa y cama en que duerma y lavalle su ropa y curalla sus enfermedades, $y$ al fin de dicho tiempo enseñada a labrar y coser y hacer cadenetas, $y$ un vestido de saya y sayuelo y ropa y camisas y manteo y sus tocados que valga veinte ducados, y seis mil maravedíes en dinero, y con esto me obligo que la dicha mi hija os servirá bien y fielmente" (Luis Astrana Marín, 2: 401).
}

Ya sabemos que Andrea vivía emancipada del hogar, con su hija, y se dedicaba a labores de costura. Pero unas semanas antes de la batalla de Lepanto, el 27 de agosto de 1571, Alonso Pacheco Portocarrero hizo en Madrid una escritura de obligación, ante el escribano Miguel de Terreros, de deberle a Andrea de Cervantes quinientos ducados (187.500 maravedís), "de precio de un collar de oro, grande, con sus perlas e piedras finas de rubíes y esmeraldas e diamantes, e una cadena de oro, grande e un Agnus Dei de oro e un rosario de cristal", los cuales 500 ducados se obligaba a satisfacer a ciertos plazos; que, sobrevenidos, fue difiriendo. Mes y medio más tarde, el 12 de octubre del mismo año 1571, Andrea daba poder a tres procuradores para un pleito que trataba "sobre ciertos maravedís e joyas", no contra Alonso, sino contra un hermano menor suyo, llamado Pedro Portocarrero (Cristóbal Pérez Pastor, 2: 17-19).

¿Qué había sucedido? ¿Qué relaciones existían entre Alonso Pacheco y Andrea de Cervantes? Y esos maravedís y joyas que ésta pleiteaba con su hermano don Pedro, ¿eran los mismos o parte de los que le adeudaba Alonso? ¿Se trataba de una sustracción del belitre La Muerte? Pero este personaje, Pedro, desaparece para entrar de nuevo en acción Alonso, no en relaciones ahora con su acreedora Andrea, sino con su hermana la más íntima de los secretos de Miguel, Magdalena de Cervantes, quien ya sabemos que se firmaba también como "Magdalena de Pimentel y Sotomayor".

Hay que mencionar que Pedro Portocarrero, alias La Muerte, se salvó juntamente con Lope Félix de Vega Carpio durante la perdida batalla de la Armada Invencible, y quién sabe si no se conocían antes o durante la batalla contra Inglaterra.

El 1 de agosto de 1575, Alonso comparece en Madrid ante el escribano Juan López del Castillo, reconoce la deuda de 1571 y ofrece entregar a Andrea los 500 ducados: la mitad para el día de Navidad de 1577 y la otra mitad el mismo día del siguiente año. Después viene esta cláusula misteriosa: "otrosí, para más abundamiento e para que estéis más segura de la paga de los dichos 
500 ducados, aunque no fuese obligado a os los pagar, como lo soy, os hago gracia dellos, por la mucha obligación e cargos en que os soy, que suman e montan mucho más que valen los dichos 500 ducados" (Cristóbal Pérez Pastor, 2: 25-28). No obstante ¿qué es lo que suma y monta mucho más que los 500 ducados? y ¿por qué ha de hacerle gracia de ellos?

Pero también Cervantes con su imperturbable serenidad, narró en la "Adjunta al Parnaso", de su Viaje, la recepción del infame soneto, "estando yo en Valladolid llevaron una carta a mi casa, para mí, con un real de porte; recibióla y pagó el porte una sobrina mía [Constanza], que nunca ella le pagara; pero dióme por disculpa que muchas veces me había oído decir que tres cosas era bien gastado el dinero: en dar limosna, en pagar al buen médico y en el porte de las cartas, ora sean de amigos o de enemigos: que las de amigos, avisan; y de las de los enemigos se puede tomar algún indicio de sus pensamientos. Diéronmela, y venía en ella un soneto malo, desmayado, sin garbo ni agudeza alguna, diciendo mal de Don Quijote; y de lo que me pesó fue del real".

La sobrina a quien se alude es, naturalmente, Constanza de Ovando, y el tiempo es, a raíz, poco más o menos, de la muerte de Gaspar de Ezpeleta, cuando la mujer de Cervantes se esfuma, por enfermedad o ausencia, de su domicilio de Valladolid y recibe y abona el porte de las cartas de su esposo, en lugar de ella, Constanza.

El 18 de diciembre, Constanza recibió de Francisco Leal 1.100 reales que le debía y por los cuales le tenía embargado. ¿De qué provenía la deuda? Se ignora. Lo cierto es que Constanza llevó a los tribunales al dicho Leal, quien sería poco leal; y por mandamiento del alcalde Juan de Aguilera, refrendado del escribano de provincia Martín de Rojas, el alguacil Francisco Vicente trabó ejecución en la persona y bienes de Leal. Sin duda asistía la razón a Constanza, pues el deudor, al advertir el mal cariz del negocio, satisfizo incontinente los 1.100 reales (Cristóbal Pérez Pastor, 2: 280-81).

Se advierte, por añadidura, este hecho significativo, que Catalina de Palacios Salazar Vozmediano, esposa de Miguel, favorece en una manda a Constanza; no tiene el menor recuerdo para Isabel de Saavedra, con quien ya estaba disgustado Cervantes a causa de incurrir en infidelidad conyugal con Juan de Urbina,

También consta de la carta de pago de fray Juan Gil y de fray Antón de la Bella, de 250 ducados que entregó Leonor de Cortinas para el rescate de Miguel (Madrid, el 31 de julio de 1579), que éste gemía cautivo "en poder de Alí Mamí, capitán de los bajeles", corroborada por otra de 50 ducados que entregó Andrea de Cervantes a los mismos redentores en igual fecha, "para ayuda del rescate de Miguel de Cervantes, su hermano, que al presente está cautivo en la ciudad de Argel en poder de Alí Mamí" (Cristóbal Pérez Pastor, Krzysztof Sliwa). Es lo único que pudo ofrecer Andrea viviendo aparte, sin poder contar con la obligación de Alonso Pacheco Portocarrero, a quien no venció hasta 1578 .

Andrea, por entonces, fue nombrada tutora de su propia hija. El 10 de octubre de 1576 dijo ante el escribano Pedro de Salazar que "Constanza de 
Figueroa, que es menor de doce años y mayor de seis, la cual es su hija y está en su poder; y para seguir sus pleitos y causas de la dicha su hija menor y cobrar sus y hacienda, le es necesario ser proveída de tutora, y ella lo quiere ser", pedía al corregidor le discerniera el cargo. ¿Qué alcance tenía éste? ¿Por qué Constanza, quien en tantos documentos aparece como hija de Nicolás de Ovando, aquí se apellida de Figueroa? ¿Por qué en la petición no se consigna el nombre del padre, ni si estaba vivo o muerto? ¿Por qué no se apunta la procedencia de los bienes que esperaba cobrar?

Ya hemos dicho cuanto era dable sobre los amores de Andrea con Ovando, sobre la ilegitimidad de Constanza y la edad segura de ésta. La tutoría tendría por objeto reclamar algo al mismo Ovando. Cierto es que no se dice que fuera difunto; pero pudo serlo; y en todo caso, muerto, vivo o ausente dejó algún legado o hacienda a su hija, que ésta tuvo que pleitear, por causas que se desconocen. Al discernimiento de la tutoría seguirían las acciones judiciales, también ignoradas. No creo que esta reclamación de bienes y hacienda estuviera directamente ligada con la necesidad de allegar fondos para el rescate de Miguel y Rodrigo, aunque coincida con el tiempo en que la familia los buscaba.

Andrea vivía con Constanza, dedicada a sus labores de costura, en la calle de la Reina, lindante con la del Baño, desde el 24 de junio de 1577. Quizá el éxito de alguna de las reclamaciones hechas como tutora de su hija le proporcionara medios para vivir independientemente. Se despojó de su dote para rescatar al hermano cautivo, cuidó a los enfermos y amigos de su padre, cosió y trabajó para ganarse el sustento, mantuvo a su madre, vieja y pobre. Andrea, después de haber tenido trato con un rico genovés, tuvo una hija de quien en documento público declara ser un español, Nicolás de Ovando, y ya sabemos que no pasó así, sino que los amores de Nicolás de Ovando con Andrea, de los que nació Constanza, ocurrieron mucho antes que las relaciones de aquélla con Juan Francisco Locadelo, el cual, aunque parezca italiano, no puede asegurarse que fuera genovés.

En consecuencia, los padres de Miguel, juntamente con su hermana Magdalena, entregaron al comendador de la Merced fray Jerónimo de Villalobos 1.077 reales, más una obligación de 200 ducados, firmada por Andrea, para que los remitiese a Valencia a Hernando de Torres. Y el 9 de junio se obligaron, además, a pagar al mercader todo lo que sobre dicha suma costara el rescate.

El 31 de julio y en escritura aparte, los redentores fray Juan Gil y fray Antón de la Bella, dentro del monasterio de la Trinidad, dieron un recibo de sus 50 ducados a Andrea y volvieron a comprometerse en iguales términos al rescate de Miguel.

En cuanto a las hermanas, Andrea continuaba soltera y viviendo aparte con su hija. Hay que señalar que Miguel buscaba a Mateo Vázquez de Leca en Thomar, y solicitó su ayuda, pues se recordaba de él por las relaciones de Nicolás de Ovando con su hermana Andrea.

Se recordará que dichos paños de tafetán pertenecían a la donación hecha en 1568 por Juan Francisco Locadelo a Andrea de Cervantes, y que ésta los 
habría regalado a su hermana. Miguel no intervino en la cesión, por hallarse ausente, ni Andrea que continuaba viviendo sola, probablemente viuda ya del florentino Sante Ambrosio.

No se ha podido determinar la fecha del casamiento, a causa de no aparecer la partida en los archivos parroquiales de Madrid. De tal enlace tampoco hay otras referencias sino la declaración de Andrea en el proceso de 1605, como "viuda, mujer que fue de Sante Ambrosio, florentín", y quien antes había sido "desposada y concertada con Nicolás de Ovando". En cuanto a la personalidad del florentino, se ignora. Tal vez era uno de muchos negociantes italianos residentes entonces en Madrid, y seguramente hermano o próximo pariente de un Julián Ambrosio, florentín, sepulto en la parroquia de San Sebastián, y del cual hemos hallado una carta de pago, hecha en Madrid el 7 de octubre de 1577, en la que se llama "residente en corte, o agente de negocios", en la del 17 de julio de 1604.

No es aventurado, pues, imaginar que Sante Ambrosio, el marido de Andrea, fuese, como Julián Ambrosio, igualmente agente de negocios o corredor de libros, y que ambos florentinos suministraran publicaciones francesas, italianas y de otros países a los mercaderes y libreros de la Corte.

Con el apartamiento de Andrea y de Miguel y la marcha de Rodrigo a Flandes, junto a Leonor de Cortinas sólo quedaron en el hogar Magdalena y Juan, el menor, que parece falleció de allí a pocos años, antes que la madre.

Aquel mismo año de 1587 que acababa de finar, surge Andrea como acreedora de una Ana de Illescas, precisamente vecina de Sevilla. Según una carta de pago fechada en Madrid el 14 de agosto, y que supone el otorgamiento previo de una obligación de la deudora y la posterior existencia de otras cartas de pago hasta el finiquito, Andrea confiesa haber recibido de Jerónimo de Valladolid, vecino de Sevilla, por mano de Luis Gallo, estante en la Corte, en el cambio de Andrés de Écija y Pedro de Villamor, 500 reales, parte de mayor suma que Jerónimo de Valladolid estaba encargado de cobrar de Ana de Illescas, vecina de Sevilla (Cristóbal Pérez Pastor, 1, documento 27). De qué provenía este débito, satisfecho a plazos, no se columbra. Quizá de la hechura y el aderezo de vestidos, pues ya sabemos que Andrea era modista. Como Jerónimo de Valladolid habría verificado otros cobros de Andrea y se entendía con Luis Gallo, Andrea no confió este asunto a su hermano Miguel, ausente por tantos pueblos.

Pero es Andrea quien nos dijo de Miguel que él era la simpatía misma y que "por su buena habilidad tiene amigos", el 30 de junio de 1605, en el proceso de Gaspar de Ezpeleta, y que disfrutaba ya en la ciudad del Sol de excelentes amistades.

Y quien sabe si el memorial, con la Información, se presentó en el Consejo de Indias el 21 de mayo, y si pasó a consulta por orden del Rey. Naturalmente, fue a parar a manos del secretario, Juan de Ledesma; y ya conocemos las relaciones de éste con la familia de Nicolás de Ovando, y el incalificable proceder de Nicolás con Andrea de Cervantes. No nos extrañaría, pues, que no se recomendara con eficacia el asunto de Miguel al Consejo. 
En aquel tiempo vemos a la sobrina Constanza de Figueroa en amores con Pedro de Lanuza y de Perellós, hermano segundo del infeliz Juan de Lanuza, Justicia de Aragón, decapitado en Zaragoza el año 1591. Eran ambos hijos de Juan de Lanuza, vizconde de Rueda y de Perellós, IV Justicia de Aragón, y de Catalina de Urrea y Toledo, vizcondesa de Rueda y de Perellós, y tenían por abuelos maternos a Juan de Lanuza, III Justicia de Aragón, y a Beatriz Despés, naturales de Zaragoza. Pero un año o dos después, quizá ya entrado el de 1595, Pedro trató a la sobrina de Cervantes y entre ambos dio principio lo que entonces llamaban: "conversación amorosa", al parecer del mismo orden que la de su madre Andrea con su padre Nicolás de Ovando, y que la de su tía Magdalena con Alonso Pacheco. De los documentos se infiere que hubo promesa matrimonial, o, al menos, esta ilusión se fraguó Constanza. Pero, Pedro procedió con Constanza como Alonso Pacheco había procedido con Magdalena, es decir, abandonándola, tras otorgarle la habitual escritura de indemnización o compensación. Otro fracaso amoroso más, que parece ser el destino de todas las mujeres de la familia de Cervantes.

En efecto, el 5 de julio de 1595 y ante el escribano Alonso de Prada, Pedro de Lanuza se obligó a pagar a Constanza de Figueroa 1.400 ducados. Pero como entonces no tenía dinero, entretuvo a su burlada amante con promesas hasta que mejorase su situación. O bien, si la escritura se hizo a raíz del martelo, desengañada enseguida Constanza, se confió en la rápida devolución de los bienes secuestrados a Lanuza. Constanza le reclamó el cumplimiento de la obligación, pero éste no se apresuró a satisfacerla, como quiera que tales juros se cobraban vencidos, sin embargo, el 3 de diciembre, el nuevo comendador otorgó poder libre y llenero a Constanza de Figueroa, "hija de Nicolás de Ovando, difunto", para que en su nombre pudiera cobrar de los administradores, arrendadores y recaudadores de las rentas reales de las sedas de Granada 1.400 ducados de a 11 reales de la renta de su encomienda de Mora. Los había de cobrar en siete años, a 200 ducados cada uno, en las pagas, que eran dos, de Navidad de aquel año de 1596; la segunda, de otros cien ducados, el día de San Juan de 1597, y así sucesivamente.

En el documento se agrega, después de otras seguridades, que los referidos 1.400 ducados eran por otros tantos que don Pedro debía pagar a Constanza "por obligación otorgada en esta dicha villa de Madrid en veinte e un días del mes de julio del año de 1595". Y termina diciendo "asimismo me obligo para que en caso de que Su Majestad me mande volver a restituir mi hacienda, como se lo tengo pedido e suplicado, dentro de diez meses como tomare la posesión de ella, daré e pagaré a la dicha doña Constanza de Figueroa o a quien por ella lo hobiere de haber cobrar, los dichos mil y quatrocientes ducados, o la parte dellos no hobiere cobrado, puestos e pagados en esta villa de Madrid e corte de Su Majestad en reales de contado" (Cristóbal Pérez Pastor, 1, documento 31).

El 8 de diciembre, Constanza "hija de Nicolás de Ovando, difunto, y de Andrea de Cervantes", se dio por contenta y pagada por Pedro de Lanuza los 1.400 ducados que se obligó a entregarle en la escritura del 25 de julio de 
1595 , los cuales había de cobrar en siete años, y en dos pagas anuales de doscientos ducados cada una, "esto saliéndole cierto la cobranza de ellos", en la forma contenida en el poder anterior.

En consecuencia, "dio por libre al dicho Pedro de Lanuza de todo y cualquier derecho que contra él tenga, aunque fuese y ser pueda pretensión de casamiento y derecho contra su hacienda". De todo, pues, se aparta y excluye, excepto de la "cobranza de los dichos 1.400 ducados". Aquí es donde dice "ser menor de veinte y cinco años, confesando como confesó ser mayor de veynte años". Ya vemos que no hay modo de hacer declarar a las mujeres su edad verdadera, cuando pasan los veintiocho. Constanza otorgó esta escritura, y con asistencia de su madre, Andrea, sin duda como asesora (Cristóbal Pérez Pastor, 1, documento 32).

Sin embargo, no hay documento donde conste que la infortunada Constanza cobró aquella donación, de la encomienda de Mora, aunque se me hace difícil sospechar que Pedro de Lanuza fuese tan mal caballero como Alonso Pacheco. Años después, Lanuza, según era de esperar, contrajo matrimonio a tono de su linaje, con Luisa de Silva y Portocarrero, dama de la reina doña Margarita de Austria, parienta del duque de Híjar. Pero Pedro, según los documentos, era bastante informal, fastuoso y tramposo, y por todas partes iba dejando deudas que no se apresuraba a satisfacer. Ninguno de los amantes de las hermanas de Cervantes era agradecido. Todos eran tramposos y desagradecidos, pues el mismo Cervantes dice: "de gente bien nacida es agradecer los beneficios que reciben, y uno de los pecados que más a Dios ofenden, es la ingratitud" (Quijote, 1, xxii); y en otro lugar se expresa de la siguiente forma: "entre los pecados mayores que los hombres cometen, aunque algunos dicen que es la soberbia, yo digo que es el desagradecimiento" (Quijote, 2, lviii). Parece que a todos los Cervantes y Cervantas, persiguió el infortunio, tan estoico y dignamente conllevado por el autor del Quijote.

Igualmente, debido a la declaración de Andrea en el proceso por la muerte de Gaspar de Ezpeleta, se conoce algo del carácter de Miguel de Cervantes, pues, ella proclama que era: "hombre que escribe e trata negocios e que por su buena habilidad tiene amigos".

El 8 de febrero de 1603, Andrea de Cervantes recibió de Diego Villela de Aldana 788 reales, importe de hechura y aderezco de camisas para Pedro de Toledo, marqués de Villafranca, duque de Fernandina, príncipe de Montalbán, capitán general de las galeras de Nápoles por el Rey nuestro señor, caballero del hábito de Santiago, comendador de la encomienda de Valderricote, y su mujer, y de lavado de ropa de Su Excelencia.

En 1605, ambas Andrea y su hija Constanza se encontraron, parece que un día y medio, aprisionadas por el proceso de la muerte de Gaspar de Ezpeleta, y ambas sostienen en un documento que no saben ¿por qué están presas? ya que no conocen a Ezpeleta. Sin embargo, sale del proceso que al cuarto de Andrea de Cervantes venían el portugués Simón Méndez y Fernando de Toledo que decían que le hacían una manga para el juego de cañas. El 6 de julio 
Andrea pide que se suelte a todos, alegando que no tenían culpa. A principios de 1606, la familia se dividió y Andrea regresó a Madrid.

El 8 de junio de 1609, recibieron el hábito de la misma Orden Tercera su hermana Andrea de Cervantes y la esposa de Miguel de Cervantes, Catalina de Palacios Salazar Vozmediano, mientras su otra hermana, Magdalena, estaba haciendo el año de noviciado para profesar también. Dicha Orden Tercera de San Francisco, de Madrid, de carácter seglar, no claustral, se había fundado en 1608; de suerte, estas tres señoras fueron de las primeras en tomar el hábito. Andrea y Catalina lo recibieron de manos del fray Diego Ordóñez, provincial. El asiento de ambas reza, respectivamente:

"D. ${ }^{a}$ Andrea de Cervantes, viuda del general Álvaro Mendaño: vive en la calle de la Magdalena, a las espaldas de la duquesa de Pastrana" (Juan Antonio Pellicer y Saforcada, ccxiii, o edición de 1800, 241-42).

Andrea no era viuda del general Álvaro Mendaño, ni podía serlo, por no haber existido tal general. El verdadero general y marino se llamaba Álvaro de Mendaña y hacía muchos años que había fallecido, y su viuda, desde 1595 , fue Isabel Barreto, avecindada en Méjico, de quien se ignora si volvió a Madrid, y tomó el hábito en aquella Orden, o lo intentó, pues algo procedería la equivocación del escribiente.

Sin embargo, cuatro meses después de recibir el hábito de la Orden Tercera, fallecía Andrea de Cervantes, en octubre de 1609, según la siguiente partida:

"En Madrid, en nueve dias del mes de otubre de mil y seiscientos y nueve años, murió de calenturas Doña Andrea de Cerbantes, viuda de Sante Ambrosi, florentin, de hedad de 65 años. Dejó una hija y no testó. Recibió los Santos Sacramentos de mano del Licenciado Francisco Lopez, tiniente de cura de la dicha iglesia. Enterróla Miguel de Cerbantes, su hermano, que ambos vivían en la calle de la Madalena, frontero de Francisco Daza, maestro de hacer coches. Enterrose en Sant Sebastián en orden de dos ducados" (Juan Antonio Pellicer y Saforcada, ccxv, y 245 de la segunda edición).

La muerte de Andrea fue un rudo golpe a las tristezas de la vejez del autor de Las novelas ejemplares. Se piensa que Magdalena amaba a Constanza, pues en su testamento le mandó a su sobrina, "hija de Andrea de Cervantes, su hermana difunta, la parte de hacienda de tres herederos que somos a la hacienda de Rodrigo de Cervantes, su hermano, que le mataron en la jornada de dos de julio del año 1601. También le mandó a Constanza sesenta y cuatro ducados de dos panyaguas que le dio Enrique de Palafox".

Constanza fue uno de los testigos declarantes que confiesa tener "treinta y ocho años poco más o menos y vivir en la calle del Baño", modernamente de Ventura de la Vega. 
La ley de la vida iba haciendo claros en la familia del autor de La Galatea. Su bondadosa sobrina Constanza de Ovando que vivía últimamente en la calle del Amor de Dios, bajaba a la tumba, sin darle tiempo para testar, aunque recibió los santos sacramentos, el 22 de septiembre de 1624. La partida de sepelio dice que la enterró Luis de Molina, secretario de Carlo Strata. Ambas, madre e hija, recibieron sepultura en el convento de San Sebastián que se construyó en 1550, así como Lope Félix de Vega Carpio.

Andrea de Cervantes vio la riqueza y la pobreza, la felicidad y la amargura, el desamparo de la fortuna y el dolor de ser engañada, y de ver a su queridísima hija, Constanza, infeliz y educada sin la presencia del padre. $\mathrm{Su}$ vida fue como la de su hermana Magdalena de Pimentel y Sotomayor, rodada de amante en amante, siguiendo otra vieja tradición familiar. Con el tiempo se trasladó a la esfera pública de su universo; sin embargo, muchos acontecimientos sucedieron en el transcurso de su triste existencia para pregonar que conducía una vida feliz. La nieta más querida de la abuela paterna, Leonor Fernández de Torreblanca, era una persona pobre, generosa, caritativa, inquieta, luchadora, pleiteante y creyente de la Santa fe católica.

\section{BIBLIOGRAFÍA UTILIZADA}

Ahmed, AbI-Ayad. "Argel: Fuente literaria de M. Cervantes", Yubaï n 2, Revista del Area de Humanidades. Universidad Autónoma de Baja California: Mexicali B.C., Mayo 1993.

-. "Argel y la huella del cautiverio en la obra cervantina". La huella del cautiverio en el pensamiento y en la obra de M. Cervantes. Madrid: Fundación Cultural Barresto, 1994. 77-89.

-. "Argel: Una etapa decisiva en la obra y pensamiento de M. de Cervantes". Actas del II Congreso Internacional de la Asociación de Cervantistas. Napoli: Instituto Universitario Orientale, 1995. 131-42.

- "El cautiverio argelino de Miguel de Cervantes". Notas y Estudios Filológicos 9 (1994): 9-17.

-. "El Cerco de Orán y de Mers-el-Kébir de 1563 et sus repercusiones literarias". Turkich Revieuw Of Middle Est Studies 7 (noviembre de 1993): 23-34.

AsEnSIO Y TOLEDo, José María. Nuevos documentos para ilustrar la vida de Miguel de Cervantes Saavedra. Sevilla, 1864.

Astrana Marín, Luis. "Nuevos documentos inéditos cervantinos. El códice de San Andrés, la familia Villafranca y la amante de Miguel de Cervantes". $A B C$ (29 de enero 1960).

-. Vida ejemplar y heroica de Miguel de Cervantes Saavedra. Madrid: Reus, 1948-58.

Avalle-ArCE, Juan Bautista de. Nuevos deslindes cervantinos. Barcelona: Ariel, 1975.

-. "La captura de Cervantes". Boletín de la Real Academia Española 48 (1968): 237-80; reimpreso en Nuevos deslindes cervantinos. Barcelona: Ariel, 1975. 277-333.

Canavaggio, Jean. "Vida y literatura: Cervantes en el Quijote". Don Quijote de la Mancha, de Miguel de Cervantes. Edición de Francisco Rico. Barcelona: Instituto Cervantes "Crítica", 1998. xli-lxvi. 
-. "Resumen cronológico de la vida de Cervantes". Don Quijote de la Mancha, de Miguel de Cervantes. Edición de Francisco Rico. Barcelona: Instituto Cervantes "Crítica", 1998. ccxliii-cclxxi.

-. Cervantès. París: Mazarine, 1986; nueva edición revisada y aumentada, París: Fayard, 1997; Cervantes. Madrid: Espasa, $1^{\text {a }}$ ed. 1987, $2^{\text {a }}$ ed. 1992, $3^{\text {a }}$ ed. 1997; Cervantes. Roma: Lucarini, 1988; Cervantes. München: Artemis, 1989; Cervantes. New York: Norton, 1990.

-. "Nueva aproximación al proceso Ezpeleta". Actas del Homenaje de los Cervantistas a José María Casasayas. Argamasilla de Alba, 1995; Cervantes 17 (1997): 25-45.

Ferrer y Ruiz Delgado, Patricio. "Documentos relativos al rescate de Cervantes". Revista de Archivos, Bibliotecas y Museos 9 (1883): 423-26.

Fitzmaurice-Kelly, James. The Life of Miguel de Cervantes Saavedra: A Biographical, Literary, and Historical Study with a Tentative Bibliography from 1585 to 1892. London, 1892. Miguel de Cervantes Saavedra: Reseña documentada de su vida. Traducción española con adiciones y enmiendas [por B. Sanin Cano]. Buenos Aires: Clydoc, 1944.

García Rey, Verardo. Nuevos documentos cervantinos hasta ahora inéditos. Madrid: "Revista de la Biblioteca, Archivo y Museo", 1929.

GONZÁLEZ Aurioles, Norberto. Monjas sevillanas parientes de Cervantes. Madrid: Viuda A. Álvarez, 1915.

Pellicer y Saforcada, Juan Antonio. Vida de Miguel de Cervantes Saavedra. Madrid, 1800

-. "Documentos que acreditan algunos sucesos descubiertos nuevamente de la vida de Miguel de Cervantes Saavedra”. Ensayo de una biblioteca de traductores españoles. Madrid, 1778. 223-48.

PÉRez PASTOR, Cristóbal. Documentos cervantinos hasta ahora inéditos. 2 vols. Madrid: Fortanet, 1897-1902.

RodríGuez Marín, Francisco. Nuevos documentos cervantinos. Madrid: Revista de Archivos, Bibliotecas y Museos, 1914; reimpreso Estudios cervantinos. Madrid: Ediciones Atlas, 1947. 175-350.

SuIwA, Krzysztof. El licenciado Juan de Cervantes. Efemérides del licenciado Juan de Cervantes. Documentos y datos para una biografía del abuelo paterno del autor del Quijote. Kassel: Edition Reichenberger, 2001.

-. Documentos cervantinos. Nueva recopilación; lista e índices. New York: Peter Lang Inc, 2000.

-. Documentos de Miguel de Cervantes Saavedra. N. ${ }^{\circ} 31$. Universidad de Navarra: Anejos de Rilce, 1999.

-. Historia del las biografías de Miguel de Cervantes Saavedra. Tallahassee, Florida State University, 1997. Tesis Doctoral.

-. "La supuesta hidalguía de Rodrigo de Cervantes, padre de Miguel de Cervantes Saavedra". Actas del IV Congreso Internacional de la Asociación de Cervantistas. Lepanto. Greece. Edición de Antonio Bernat Vistarini. Palma de Mallorca, Universidad de les Illes Balears, 2000. 131-38.

-. "Hija y nieta de Miguel de Cervantes Saavedra, Isabel de Cervantes y Saavedra e Isabel Sanz". Actas del VIII Coloquio Internacional de la Asociación de Cervantistas. El Toboso: Ediciones Dulcinea de El Toboso, 1999. 267-74.

-. "Un documento inédito sobre el cautiverio de Miguel de Cervantes". Anales cervantinos 34 (1998): 343-47. 
-. "La dualidad de Leonor de Cortinas, madre de Miguel de Cervantes Saavedra genio de la literatura española". Actas del XIII Congreso de la Asociación Internacional de Hispanistas. Vol. 1 Medieval, Siglos XVI-XVII. Madrid: Editorial Castalia, 1998. 758-63.

TORRE y DEl CERro, José de la. "Cinco documentos cervantinos." Boletín de la Real Academia de Ciencias, Bellas Letras y Nobles Artes de Córdoba 4 (1925): 169-83.

-. La familia de Miguel de Cervantes; apuntes genealógicos y biográficos, fundamentados en documentos cordobeses. Córdoba: "La Comercial", 1923.

Torres LanZas, Pedro (Edición). "Información de Miguel de Cervantes de lo que ha servido a S. M. y de lo que ha hecho estando captivo en Argel, y por la certificación que aquí presenta del Duque de Sesa se verá como cuando le captivaron se le perdieron otras muchas informaciones, fees y recados que tenía de lo que había servido a S. M". Revista de Archivos, Bibliotecas y Museos $3^{\mathrm{a}}$ serie, 5 (1905): 345-97. Reimpreso en forma de libro con el mismo título: Información de Miguel de Cervantes de lo que ha servido a S.M y de lo que ha hecho estando captivo en Argel y por la certificación que aquí presenta del duque de Sesa se verá como cuando le captivaron se le perdieron otras muchas informaciones, fees y recados que tenía de lo que había servido a S.M. Madrid: José Esteban, 1981.

Velasco y Santos, Miguel. "Documento sobre el rescate de Cervantes". Revista de Archivos, Bibliotecas y Museos 2.5 (1873): 1-8.

\section{Resumen}

Por primera vez sale a la luz un trabajo completo sobre Andrea de Cervantes y su hija Constanza Ovando y Figueroa, hermana y sobrina, respectivamente, de Miguel de Cervantes Saavedra. Sobre la hermana del autor de "La Galatea" hay unos 25 documentos legales; pero no existe ningún esbozo completo de su perfil, aunque era la nieta predilecta de Leonor Fernández de Torreblanca, abuela paterna del Manco de Lepanto. En este trabajo esbozaré lo que se ha podido hacer con los datos no explotados, presentando una breve biografía de Andrea, así como toda la información sobre su hija Constanza, fruto de amores de Nicolás de Ovando.

Palabras claves: Andrea de Cervantes, Costanza de Ovando, Nicolás de Ovando, biografía.

\section{Summary}

For the first time a complete work is presented about Andrea de Cervantes and her daughter Constanza Ovando y Figueroa, sister and nice of Miguel de Cervantes Saavedra, respectively. About the sister of the author of "The Galatea" there are some 25 legal documents, but no complete outline of her profile exists, although she was the dearest granddaughter of Leonor Fernández de Torreblanca, paternal grandmother of Manco de Lepanto. In this article I will outline what has not been done with the unexplored documents, and this way I present a brief biography of Andrea, as well as all the information about her daughter Constanza, fruit of her affair with Nicolás de Ovando.

Key works: Andrea de Cervantes, Costanza de Ovando, Nicolás de Ovando, biography. 